\title{
A circadian rhythm sleep disorder: melatonin resets the biological clock
}

\author{
${ }^{1}$ A Abbas, ${ }^{2} \mathrm{~J}$ Raju, ${ }^{3} \mathrm{~J}$ Milles, ${ }^{4} \mathrm{~S}$ Ramachandran \\ ${ }^{1}$ Foundation Year 1 Trainee; ${ }^{2}$ Senior Biochemist, Department of Clinical Biochemistry; ${ }^{3}$ Consultant Physician, Department of Diabetes and \\ Endocrinology; ${ }^{4}$ Consultant Chemical Pathologist, Department of Clinical Biochemistry, Heart of England NHS Foundation Trust, Sutton \\ Coldfield, UK
}

\begin{abstract}
Circadian rhythm sleep disorders are poorly understood and often misdiagnosed.They are all related to the timing of sleep within the 24-hour day. This paper describes a patient with a long history of sleep disturbance whom we diagnosed as having delayed sleep phase syndrome by history and measurement of urinary melatonin metabolite excretion. Literature on the characteristics, diagnosis and management of this syndrome are briefly reviewed. In addition, the relation of the neurohormone melatonin to circadian rhythm and its other physiological roles are described.
\end{abstract}

KEYWORDS Circadian rhythm sleep disorders, delayed sleep phase syndrome, melatonin, 6-sulphatoxymelatonin
Correspondence to S Ramachandran, Department of Clinical Biochemistry, Good Hope Hospital, Heart of England NHS Foundation Trust, Rectory Road, Sutton Coldfield, West Midlands B75 7RR, UK

tel. +44 (0) I 2 I 4247246 e-mail sud.ramachandran@ heartofengland.nhs.uk

\section{CASE REPORT}

A 53-year-old Caucasian man with a body mass index of 32 was referred to our metabolic clinic by his general practitioner with a l4-year history of chronic sleep disturbance and fatigue. The patient complained of being unable to sleep before $03.00-04.00$ and found it extremely difficult to wake up for work at about 08.00. If left undisturbed, usual waking times were around 12.00-13.00. The patient also described occasional days where he would have a 24-48-hour period without sleep, followed by prolonged sleep usually lasting about 15 hours. Prior to presentation he had consulted many physicians and tried hypnotic medication with no effect. Apart from an episode of bacterial epiglottitis in 1994, there was no other significant medical history and his clinical examination was unremarkable.

Basic laboratory investigations, including full blood count, liver function tests and urea and electrolytes, were all within normal limits. A morning (09.00) pituitary profile revealed an abnormally low cortisol (86 nmol/l) with luteinising hormone, follicle-stimulating hormone, prolactin, thyroid-stimulating hormone and free T4 all within normal range. A normal response to a short synacthen test excluded hypoadrenalism. The patient's magnetic resonance imaging brain scan was normal, and sleep oximetry revealed no significant hypoxia. At this point, delayed sleep phase syndrome (DSPS) was clinically suspected (Table I). Timed urinary 6-sulphatoxymelatonin (aMT6), a melatonin metabolite that correlates well with serum melatonin secretion, was measured over two days in urinary aliquots by radioimmunoassay. An abnormal melatonin secretion pattern was noted, with urinary aMT6 only starting to rise at about 03.00 on both days (Figure I), whereas it was expected to have risen about six hours previously.

\begin{tabular}{|c|c|}
\hline $\begin{array}{l}\text { Circadian } \\
\text { rhythm sleep } \\
\text { disorder }\end{array}$ & Essential features \\
\hline $\begin{array}{l}\text { Time zone } \\
\text { change (jet lag) } \\
\text { syndrome }\end{array}$ & $\begin{array}{l}\text { Difficulty in initiating or maintaining sleep, } \\
\text { excessive sleepiness, decreased daytime } \\
\text { alertness and performance following } \\
\text { rapid travel across multiple time zones }\end{array}$ \\
\hline $\begin{array}{l}\text { Shift work sleep } \\
\text { disorder }\end{array}$ & $\begin{array}{l}\text { Insomnia or excessive sleepiness that } \\
\text { occurs as a transient phenomenon in } \\
\text { relation to work schedules }\end{array}$ \\
\hline $\begin{array}{l}\text { Irregular sleep- } \\
\text { wake pattern }\end{array}$ & $\begin{array}{l}\text { Temporally disorganised and variable } \\
\text { episodes of sleeping and waking behaviour }\end{array}$ \\
\hline $\begin{array}{l}\text { Delayed sleep } \\
\text { phase syndrome }\end{array}$ & $\begin{array}{l}\text { Major sleep episode is delayed in relation } \\
\text { to desired clock time with resulting } \\
\text { sleep-onset insomnia or difficulty in } \\
\text { waking at desired time }\end{array}$ \\
\hline $\begin{array}{l}\text { Advanced sleep } \\
\text { phase syndrome }\end{array}$ & $\begin{array}{l}\text { Major sleep episode is advanced in } \\
\text { relation to desired clock time, resulting in } \\
\text { compelling evening sleepiness, early sleep } \\
\text { onset and waking earlier than desired }\end{array}$ \\
\hline $\begin{array}{l}\text { Non-24-hour } \\
\text { sleep-wake } \\
\text { cycle }\end{array}$ & $\begin{array}{l}\text { Chronic steady pattern comprising } \\
\text { one- to two-hour daily delays in sleep } \\
\text { onset and wake times }\end{array}$ \\
\hline
\end{tabular}

Adapted from: American Academy of Sleep Medicine. International classification of sleep disorders: diagnostic and coding manual. 2 nd ed. Westchester, Illinois: American Academy of Sleep Medicine; 2005.

The diagnosis of DSPS was confirmed and the patient was started on $3 \mathrm{mg}$ of oral melatonin at 20.00. His sleeping pattern returned to normal with sleep onset between 22.30-23.30 and waking around 08.00. Repeat measurement of his urinary aMT6 excretion revealed a normal physiological pattern (Figure 2). The phase 


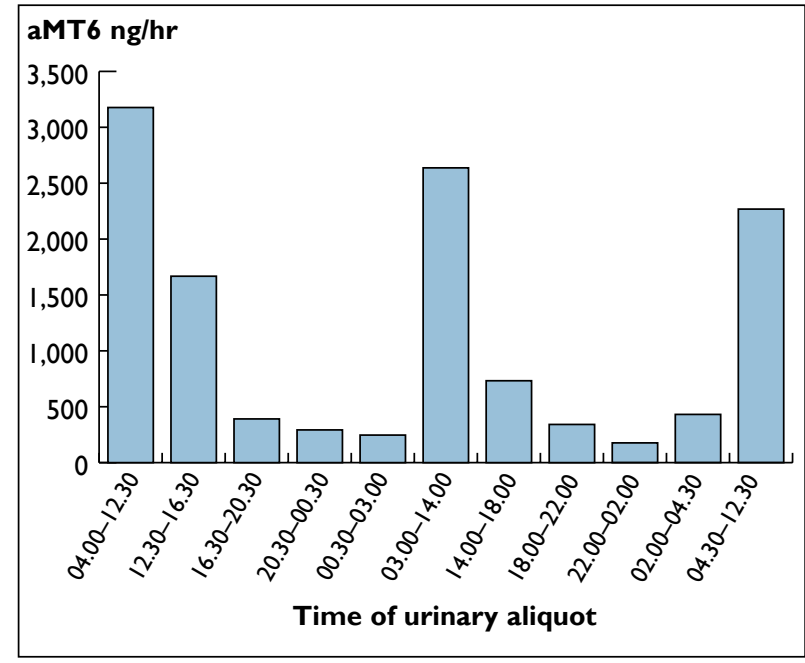

FIGURE I The pattern of pre-treatment urinary melatonin metabolite - aMT6 (collected at timed aliquots).

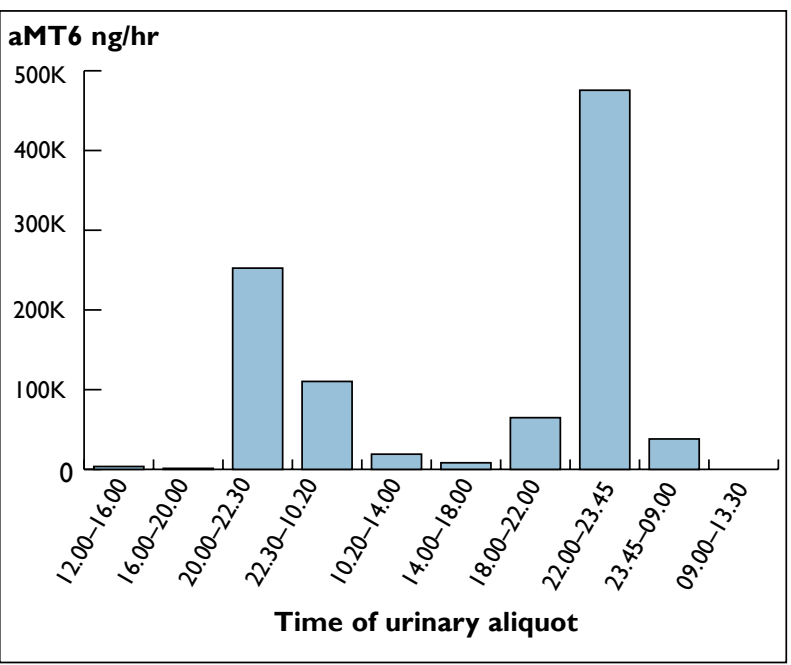

FIGURE 2 The pattern of post-treatment urinary melatonin metabolite - aMT6 (collected at timed aliquots).

advance of sleep also coincided with a near threefold rise in morning (09.00) cortisol $(256 \mathrm{nmol} / \mathrm{l})$.

\section{DISCUSSION}

Sleep-related complaints are common, with insomnia and associated daytime dysfunction reported in 10-34\% of patients attending primary care.' Circadian rhythm sleep disorders (CRSDs) are characterised by a lack of synchronisation between a person's biological clock and the environmental 24-hour schedule. ${ }^{2}$ The central circadian pacemaker or 'master' biological clock consists of a specialised group of neurons in the suprachiasmatic nucleus of the hypothalamus. This central pacemaker regulates circadian rhythms such as the sleep-wake cycle, body temperature and the secretion of hormones, including melatonin, from the pineal gland. ${ }^{3}$

Few large-scale studies on patients with CRSDs have been performed and data on prevalence remain scarce. ${ }^{2}$
Six categories of CRSDs have been described (Table I) and studies indicate that the majority of these patients were suffering from DSPS. ${ }^{2,4}$

In DSPS, sleep-onset and wake times are intractably delayed, with extreme difficulty in waking at the desired time in the morning. There is a relative inability to advance the sleep phase to earlier hours. ${ }^{4}$ Sporadic non-circadian days may also occur (with no sleep for an entire day, night and even part of the next day), followed by a prolonged period of sleep lasting $12-18$ hours. ${ }^{4}$ In addition to the abnormal timing of the sleep-wake cycle in DSPS, other circadian rhythms such as core body temperature and the hormonal secretion of melatonin and cortisol have also been reported to be delayed. ${ }^{5,6}$ The circadian secretion of melatonin normally rises at about 21.00 , peaks at 03.00 and is barely detectable at 09.00. ${ }^{7}$

The disorder is best diagnosed by clinical interview and a week of actigraphy (gross motor activity monitoring) or sleep diary. Melatonin secretion pattern and core body temperature measurement over 36 hours are additional diagnostic tools. ${ }^{2}$ Polysomnography has been described as inadequate in the assessment of CRSDs. ${ }^{2}$

The exact cause of DSPS remains unclear. Various genetic factors such as the HLA DRI serotype and structural polymorphisms in the human period 3 (hPer3) gene have been associated with DSPS. ${ }^{8,9}$

The aim of treatment in DSPS is to advance the onset of the sleep phase. Recognised means of achieving this include chronotherapy (a behavioural technique), brightlight therapy and daily timed melatonin administration., ${ }^{210}$ Melatonin has been described as a 'chronobiotic', referring to its capability to synchronise circadian rhythm. The ability of exogenous melatonin to phaseadvance the circadian clock, as seen in our patient, may be attributed to its action on melatonin receptors (MT2) in the suprachiasmatic nucleus."

Endogenous pineal melatonin secretion is normally under the control of the suprachiasmatic nucleus, which receives input about the environmental light/dark cycle via the retinohypothalamic tract. Thus by measuring the pattern of melatonin secretion it is possible to obtain a picture of the 'timing' of the central pacemaker, ${ }^{3}$ which in our patient (Figure I) was markedly abnormal. Melatonin is involved in the mediation of sleep, most likely by inhibiting the circadian wakefulness generating mechanism. Although there is strong evidence to suggest that melatonin plays an important role in the pathophysiology of CRSDs, additional large-scale studies are needed to elucidate whether abnormal melatonin secretion is a causal factor in these disorders. ${ }^{12}$ Melatonin is also being extensively investigated for its diverse antioxidant, oncostatic and immunomodulatory properties. ${ }^{3}$ 


\section{CONCLUSION}

We described a patient with a characteristic history of DSPS. It is important to be aware of CRSDs, as in our patient the delay in his diagnosis and treatment had a significant impact on his quality of life. The aim of treatment in all CRSDs is to restore normal circadian pattern, and this was achieved effectively in our patient with exogenous melatonin.

\section{REFERENCES}

I Sateia MJ, Nowell PD. Insomnia. Lancet 2004; 364:1959-73. doi:10.1016/S0I40-6736(04) I7480-I

2 Dagan Y. Circadian rhythm sleep disorders (CRSD). Sleep Med Rev 2002; 6:45-54. doi:I0.1053/smrv.200I.0190

3 Blask DE. Melatonin, sleep disturbance and cancer risk. Sleep Med Rev 2009; 13:257-64. doi:10.1016/j.smrv.2008.07.007

4 American Academy of Sleep Medicine. International classification of sleep disorders: diagnostic and coding manual. 2nd ed. Westchester, Illinois: American Academy of Sleep Medicine; 2005.

5 Shibu K, Uchiuama M, Kim K et al. Melatonin, cortisol and thyroidstimulating hormone rhythms are delayed in patients with delayed sleep phase syndrome. Sleep Biol Rhythms 2003; 1:209-14. doi:10.1046/j.1446-9235.2003.00058.x

6 Oren DA, Turner EH, Wehr TA. Abnormal circadian rhythms of plasma melatonin and body temperatures in the delayed sleep phase syndrome. J Neurol Neurosurg Psychiatry 1995; 55:665-70.

7 Lack LC, Wright HR. Treating chronobiological components of chronic insomnia. Sleep Med 2007; 8:637-44. doi:10.1016/j. sleep.2006.10.003

8 Hohjoh H, Takahashi Y, Hatta Y et al. Possible association of human leucocyte antigen DRI with delayed sleep phase syndrome. Psychiatry Clin Neurosci 1999; 53:527-9. doi:I0.1046/j.I440-1819.1999.00574.x

9 Ebisawa T, Uchiyama M, Kajimura $\mathrm{N}$ et al. Association of structural polymorphisms in the human period3 gene with delayed sleep phase syndrome. EMBO Rep 2001; 2:342-6. doi:10.1093/emboreports/kve070

10 Sack RL, Auckley D, Auger RR et al. Circadian rhythm sleep disorders: part II, advanced sleep phase disorder, delayed sleep phase disorder, free-running disorder, and irregular sleep-wake rhythm. Sleep 2007; 30: I484-50I.

I L Liu C,Weaver DR, Jin $X$ et al. Molecular dissection of two distinct actions of melatonin on the suprachiasmatic circadian clock. Neuron 1997; 19:9I-102. doi:I0.10I6/S0896-6273(00)80350-5

12 Pandi-Perumal SR, Trakht I, Spence DW et al. The roles of melatonin and light in the pathophysiology and treatment of circadian rhythm sleep disorders. Nat Clin Pract Neurol 2008; 4:436-47. doi:10.1038/ncpneuro0847

\section{UPDATE COURSE ON ELDERLY MEDICINE}

\section{Monday 16 - Friday 20 May 2011}

\section{Course Director: Dr Andrew T Elder, FRCP Edin, Consultant Geriatrician}

This biennial course offers a valuable opportunity to discuss clinical issues in elderly care. Places are limited to 60 so early application is advised.

Although the course is designed to appeal to non-UK-based consultants, specialists and senior trainees in elderly medicine, from January $201 \mathrm{I}$ places are also available for doctors resident or working in the UK. Attendance at part of the course is also possible.

Each day will focus on a single clinical topic:

- Monday: Preventing readmission of elderly people

- Tuesday: First do no harm

- Wednesday (half-day): Practical psychiatry for geriatricians

- Thursday: Stroke disease

Friday (half-day): Mobility and function

\section{COURSE FEES:}

Weekly rate: $€ 720$ (inc.VAT) Daily rate:

Mon, Tues, Thurs $£ 200$ (inc.VAT)

Wed, Fri $€ 100$ (inc. VAT)

Late registration fee: $£ 50$ if registering after 4 April 2011

For further details please see: http://events.rcpe.ac.uk or contact: Christina Gray, Education, Training and Standards Department, Royal College of Physicians, 9 Queen Street,

Edinburgh EH2 IJQ, UK

Tel: +44(0) I3। 2473607

Email: c.gray@rcpe.ac.uk 